This is the final peer-reviewed accepted manuscript of:

Benito, P., et al. "Stable Rh Particles in Hydrotalcite-Derived Catalysts Coated on FeCrAlloy Foams by Electrosynthesis." Applied Catalysis B: Environmental, vol. 179, 2015, pp. 321-332.

The final published version is available online at : http://dx.doi.org/10.1016/j.apcatb.2015.05.035

Rights / License:

The terms and conditions for the reuse of this version of the manuscript are specified in the publishing policy. For all terms of use and more information see the publisher's website.

This item was downloaded from IRIS Università di Bologna (https://cris.unibo.it/)

When citing, please refer to the published version. 


\section{Stable Rh particles in Hydrotalcite-derived Catalysts coated on FeCrAlloy foams by}

\section{Electrosynthesis}

Patricia Benito $^{1 *}$, Gert Nuyts ${ }^{2}$, Marco Monti ${ }^{1}$, Wout De Nolf ${ }^{2}$, Giuseppe Fornasari ${ }^{1}$, Koen Janssens $^{2}$, Erika Scavetta ${ }^{1}$, Angelo Vaccari ${ }^{1}$

${ }^{1}$ Dipartimento di Chimica Industriale “Toso Montanari”, Università di Bologna, Viale Risorgimento 4, 40136, Bologna, Italy

${ }_{4}^{2}$ Department of Chemistry, University of Antwerp, Groenenborgerlaan 171, 2020 Antwerp, Belgium

*corresponding author

patricia.benito3@unibo.it

Dipartimento Chimica Industriale "Toso Montanari"

ALMA MATER STUDIORUM-Università di Bologna

Viale Risorgimento 4, 40136

Bologna, Italy

Tel.: +39 0512093677; fax: +390512093679 ha formattato: Inglese (Regno Unito)

ha formattato: Inglese (Regno Unito)

ha formattato: Italiano (Italia)

ha formattato: Italiano (Italia) 


\section{ABSTRACT}

The metal particle size distribution coating, thickness and activity of electrosynthesised hydrotalcite-derived $\mathrm{Rh}$-structured catalysts for the partial oxidation of $\mathrm{CH}_{4}$ to syngas were optimized. Several parameters were modified during the electro-base precipitation of hydrotalcite-type compounds on the surface of FeCrAlloy foams. The $\mathrm{Rh} / \mathrm{Mg} / \mathrm{Al}$ atomic ratio, total metal concentration and the presence of $\mathrm{Ni}$ as a second active phase in the electrolytic solution were the parameters investigated by SEM-EDS, $\mu$ XRF/XANES and catalytic tests under diluted and concentrated reaction mixtures.

The amount of rhodium species, present as $\mathrm{Mg}\left(\mathrm{Rh}_{\mathrm{x}} \mathrm{Al}_{1-\mathrm{x}}\right)_{2} \mathrm{O}_{4}$, depended on the thickness of the $\underline{\text { electrosynthesised layer as well as the rhodium particle size }}$ and dispersion. Smaller and more dispersed particles were obtained as the Rh concentration in the electrolytic solution decreased from $\mathrm{Rh} / \mathrm{Mg} / \mathrm{Al}=11 / 70 / 19$ to $5 / 70 / 25$ and 2/70/28 atomic ratio \% (a.r. \%) and in thinner rather than in thicker layers. A narrow particle size distribution centred at $10 \mathrm{~nm}$ was obtained for the $\mathrm{Rh} / \mathrm{Mg} / \mathrm{Al}=2 / 70 / 28$ a.r. \%. Despite the improvement in metallic particles features, the $\mathrm{CH}_{4}$ conversion was negatively affected by the lower amount of active sites in the coating, the high metal support interaction and possibly the oxidation of metallic particles and carbon formation.

By increasing the total metal concentration from $0.03 \mathrm{M}$ to $0.06 \mathrm{M}$ with the $\mathrm{Rh} / \mathrm{Mg} / \mathrm{Al}=5 / 70 / 25$ a.r. \% a larger amount of solid containing well dispersed rhodium particles was deposited and catalytic performances enhanced. The inclusion of $\mathrm{Ni}$ as second active phase gave rise to a very active bimetallic RhNi catalysts, $\mathrm{CH}_{4}$ conversion and selectivity to syngas were above $90 \%$, but it slightly deactivated with time-on-stream.

Keywords: Electrosynthesis, $\mathrm{Rh}, \mathrm{RhNi}, \mathrm{FeCrAlloy}$, Catalytic partial oxidation of $\mathrm{CH}_{4}$ 


\section{Introduction}

The Catalytic Partial Oxidation (CPO) of methane is nowadays an industrial option to autothermally produce syngas at short contact time values [1]. The active catalysts reported in literature for this process are metals $(\mathrm{Ni}, \mathrm{Co}, \mathrm{Pt}, \mathrm{Rh})$ supported on or included in ceramic materials $\left(\gamma-\mathrm{Al}_{2} \mathrm{O}_{3}, \alpha-\mathrm{Al}_{2} \mathrm{O}_{3}, \mathrm{MgO}, \mathrm{MgAl}_{2} \mathrm{O}_{4}, \mathrm{CeO}_{2}, \mathrm{Ce}_{1-\mathrm{x}} \mathrm{Zr}_{\mathrm{x}} \mathrm{O}_{2}\right)$ [2]. Experimental and theoretical studies demonstrated that the catalytic bed is divided in an oxidation and a reforming zone [3-5]. In the short oxidation zone, located at the inlet of the bed, partial and total oxidation products are formed, the temperature largely increases, and $\mathrm{O}_{2}$ consumption is mass transfer limited. In the reforming zone, $\mathrm{CH}_{4}$ is consumed by Steam Reforming (SR). Water Gas Shift (WGS) and reverse Water Gas Shift (rWGS) reactions occur along the whole catalytic bed [6]. The high Gas Hourly Space velocities (GHSV) required to operate at short contact times increase the heat released by exothermic reactions. Such high temperatures promote homogeneous reactions [7], deactivate the catalyst and lead to safety risks [8,9]. Several efforts were made to keep the temperature under control, which deal either with the design of the reactor during CPO scale-up [1] or with the use of structured catalysts on laboratory scale.

Structured catalysts are made of a three-dimensionally shaped support (i.e. honeycomb, opencell foam, fibre) coated by a catalytic film [10]. The requirements that a CPO catalyst must meet [2,11] (high $\mathrm{CH}_{4}$ conversion and selectivity to syngas, stability against sintering, oxidation and carbon formation, fast start-up response) are related to both support and coating features. In particular, they depend on metal species and support forming the coating film, its homogeneity, adhesion and, last but not least, on the stability of the support under the harsh $\mathrm{CPO}$ reaction conditions. Hence, the success of a CPO structured catalyst is the result of the coating chemical formulation, support morphology and shape, preparation route and catalyst3D support interaction. 
As material for the support, honeycombs and open-cell foams made by ceramic (cordierite [1214], $\left.\alpha-\mathrm{Al}_{2} \mathrm{O}_{3}[3,15,16], \mathrm{SiC}[17]\right)$ and metallic (Ni [18,19], FeCrAlloy [20-23]) materials are mainly employed.

Under adiabatic operative conditions the start-up, steady-state and blow-out of the CPO depend on the shape of the support $[24,25] . \mathrm{O}_{2}$ mass transfer and therefore the heat released by exothermic reactions is controlled by the size and shape of the channels in honeycomb monoliths [26,27]. In non-adiabatic reactors, radiative heat loss helps to decrease hot spots $[28,29]$. Lastly, the heat transfer by conduction also plays a role in flattening thermal profiles when using thermally conductive supports $[17,22]$.

The lower amount of active catalyst per volume in structured catalysts with respect to pelletized catalysts [10] is usually balanced by depositing a highly active catalyst. Indeed, noble metals, mainly $\mathrm{Pt}[12,15]$ and $\mathrm{Rh}[16,30]$, are the active species, although the use of bimetallic noble metal-nickel or -cobalt catalysts [31] and stratified beds [32] was also reported. The amount of active species, which modifies the thermal profile $[8,16,26]$, may be controlled by pore size [33], layer thickness [34] and active phase loading [30].

Washcoating or dip-coating or their modifications such as dip-blowing [35,36] are often adopted to obtain metal supported CPO structured catalysts. The metals are incorporated by impregnation as their respective salts either before [9,14,29] or after [13,16,23] washcoating the ceramic support, as well as directly on the surface of the structured support $[12,15,30]$. The impregnation on structured supports may give rise to dishomogeneities in the metal dispersion. Contrarily, deposition of $\mathrm{Pt}$ nanoparticles on $\alpha-\mathrm{Al}_{2} \mathrm{O}_{3}$ foams by microwave-assisted gelcombustion synthesis in self-propagating mode [37], spontaneous deposition of $\mathrm{Rh}$ and $\mathrm{Pt}$ particles on Ni foams by metal exchange reactions [19] or electrosynthesis of Rh on FeCrAlloy foams [23] produce small, well-dispersed and distributed metallic particles. 
Low surface area supports such as $\alpha-\mathrm{Al}_{2} \mathrm{O}_{3}$ may lead to large metallic particles with low dispersion $[15,16]$ and small metal-support interaction. These features, coupled to the harsh CPO reaction conditions, give rise to changes in the catalyst and, eventually, to its deactivation, depending on the position within the catalytic bed [15]. In the case of Pt catalysts, metallic species may even be transported from the oxidation to the reforming zone, accompanied by oxidation of $\mathrm{Pt}^{0}$ to $\mathrm{PtO}_{2}$, sintering [15,30], and carbon formation [15]. On the other hand, $\mathrm{Rh}$ catalysts are more stable [3] and the carbon formation is lower [38]; however, if $\mathrm{Rh}^{0}$ particles are not well stabilized, they also suffer from sintering [23]. The oxidation state of Rh during $\mathrm{CPO}$ tests is related to operative conditions; at high temperatures $\left(700-1000{ }^{\circ} \mathrm{C}\right) \mathrm{Rh}$ is in a reduced state even in the presence of oxygen [39], while at temperatures around $400^{\circ} \mathrm{C} \mathrm{Rh}^{3+}$ is detected in the oxidation zone [40].

Supports, such as $\gamma-\mathrm{Al}_{2} \mathrm{O}_{3}$ [16,33], $\gamma-\mathrm{Al}_{2} \mathrm{O}_{3}$ modified by Ce [16], La or P [13,23], $\mathrm{AlPO}_{4}$ [23], perovskites $\left(\mathrm{LaMnO}_{3}\right.$ [17] and $\mathrm{LaCoO}_{3}$ [31]) improve $\mathrm{Rh}$ dispersion and stability. However, special care must be taken during washcoating since the catalyst support may suffer from changes. For instance the wet ball milling step used for the preparation of an $\mathrm{AlPO}_{4}$ slurry induces pore collapse and decreases the surface area [23].

Hydrotalcite-type (HT) compounds are well-known precursors of catalysts for CPO, since after calcination and reduction small metallic particles are well stabilized inside a thermally stable oxide matrix [41]. Hence it was proposed by some of us to prepare Rh-bulk catalysts coated on FeCrAlloys by thermal decomposition of electrosynthesized electrosynthesised HT compounds [42-48]. The thermal conductivity of FeCrAlloy is not very high [10]; however, finding a metallic support able to withstand CPO conditions is not straightforward. The synthesis procedure consists of the precipitation of HT compounds on the surface of the metallic support by an electro-base generation method [49]. The reduction of nitrates in aqueous media by application of a cathodic potential produces hydroxyls at the electrode surface, increasing the 
local $\mathrm{pH}[50]$. Despite the electrosynthesis being a promising alternative to the washcoating of HTs [51], several aspects need further improvement. Due to the thin film thicknesses obtained in our first experiments, the number of active sites were increased by using electrolytic solutions with a high $\mathrm{Rh}$ loading $[\mathrm{Rh} / \mathrm{Mg} / \mathrm{Al}=11 / 70 / 19$ a.r. \%], however $\mathrm{Rh}$ particles were quite large (50-200 nm) [48]. Moreover, the coating film was not homogeneous, since it was composed by an inner and outer layer, differing in composition. The latter was enriched in cations that precipitate at lower $\mathrm{pH}$, i.e. $\mathrm{Al}$ and $\mathrm{Rh}$, indicating an uncontrolled precipitation as the synthesis proceeded. This phenomenon may be ascribed to sequential precipitation of the elements due to an insulating effect of the deposits [45,52], and to mass transfer phenomena [50].

Aim of this paper was to reduce the amount of $\mathrm{Rh}$ in the catalytic film without decreasing catalytic performances by optimizing the Rh particle size, film thickness and active phase composition. Firstly, to decrease the metal particle size and the sintering, the $\mathrm{Rh} / \mathrm{Mg} / \mathrm{Al}$ a.r. \% in the electrolytic solution was modified from $11 / 70 / 19$ used in our previous works [48] to $5 / 70 / 25$ and 2/70/28. Secondly, to overcome the loss in active sites by lowering the Rh loading, the metal concentration in the $\mathrm{Rh} / \mathrm{Mg} / \mathrm{Al}=5 / 70 / 25$ a.r. \% electrolytic solution was increased from $0.03 \mathrm{M}$ to $0.06 \mathrm{M}$ and $0.1 \mathrm{M}$ to favour the transport rate of the species towards the working electrode and to increase the amount of solid deposited [53,54]. Lastly, to improve the activity a second active phase, $\mathrm{Ni}$, was added in the coating to form RhNi bimetallic catalysts [55], the bimetallic RhNi catalyst being prepared by replacing a part of the $\mathrm{Mg}^{2+}$ by $\mathrm{Ni}^{2+}(\mathrm{Rh} / \mathrm{Ni} / \mathrm{Mg} / \mathrm{Al}$ $=5 / 15 / 55 / 25$ a.r. \%). The morphology and composition of the samples were analysed by Scanning Electron Microscopy - Energy Dispersive X-ray Spectroscopy (SEM-EDS), and microscopic X-Ray Fluorescence ( $\mu \mathrm{XRF}$ ), while X-ray Absorption Near Edge Structure (XANES) spectroscopy, measuring the $\mathrm{Rh}-\mathrm{L}_{3}$ line, was used in order to determine the $\mathrm{Rh}$ speciation. The catalyst activity was studied by performing CPO tests feeding concentrated and diluted $\mathrm{CH}_{4} / \mathrm{O}_{2} / \mathrm{He}$ gas mixtures and operating at the oven temperature of $750{ }^{\circ} \mathrm{C}$. 


\section{Experimental part}

\subsection{Synthesis of the catalysts}

Electrosynthesis was performed in a single compartment three electrode cell at room temperature, with a $1.00 \times 1.19 \mathrm{~cm}^{2}$ cylinder of FeCrAlloy foam (60 ppi and $4.5 \%$ nominal relative density) as Working Electrode (WE). Prior to synthesis, cylinders were rinsed with ethanol and water and electrode potentials were measured with respect to an aqueous Saturated Calomel Electrode [SCE; i.e. Reference Electrode (R.E.)]. The Counter Electrode (C.E.) was a Pt gauze (about $18.00 \mathrm{~cm}^{2}$ ) placed around the foam cylinder at approx. $0.70 \mathrm{~cm}$. To establish an electrical contact between the foam and the potentiostat, a Pt wire was inserted in the middle of the foam cylinder and two other Pt wires perpendicular to the previous one in the outer surface of the foam [48]. Pt wires were well insulated by two layers of teflon tape and parafilm, to avoid their contact with the electrolytic solution and thus ensuring that only the FeCrAlloy acted as the working electrode.

Electrochemical syntheses were carried out by chronoamperometry with an Autolab PGSTAT128N (Metrohm) at -1.2 V vs SCE for $2000 \mathrm{~s}$ as identified in our previous work [48]. The electrolytic solution was an aqueous solution containing the salts of the cations to be precipitated $\left[\mathrm{Rh}\left(\mathrm{NO}_{3}\right)_{3}, \mathrm{Mg}\left(\mathrm{NO}_{3}\right)_{2}, \mathrm{Al}\left(\mathrm{NO}_{3}\right)_{3}\right.$ and $\left.\mathrm{Ni}\left(\mathrm{NO}_{3}\right)_{2}\right]$ with a total concentration of 0.03 , 0.06 or $0.10 \mathrm{M}$. The $\mathrm{Rh} / \mathrm{Mg} / \mathrm{Al}$ atomic ratio in the solution was varied (from $11 / 70 / 19$ to $5 / 70 / 25$ and $2 / 70 / 28$, a.r. \%), while the $\mathrm{Rh} / \mathrm{Ni} / \mathrm{Mg} / \mathrm{Al}$ ratio was $5 / 15 / 55 / 25$ a.r. $\%$. $\mathrm{KOH}$ was added to adjust the initial $\mathrm{pH}$ of the solution to 3.8 [44]. After washing and drying at $40{ }^{\circ} \mathrm{C}$, coated foam cylinders were weighed. Samples obtained by electrosynthesis using the $0.03 \mathrm{M}$ solution of $\mathrm{Rh} / \mathrm{Mg} / \mathrm{Al}$ will from now be referred to as $\mathrm{RhX}-\mathrm{HT}$, where $\mathrm{X}$ refers to the Rh amount (a.r. \%) i.e. Rh11-HT. Bimetallic samples will be named Rh5Ni-HT, while the samples prepared from the $0.06 \mathrm{M}$ and $0.10 \mathrm{M}$ solutions Rh5-HT-0.06M and Rh5-HT-0.1M. 
Catalysts were obtained by calcination of coated foams at $900{ }^{\circ} \mathrm{C}$ for $12 \mathrm{~h}$ (heating rate $10{ }^{\circ} \mathrm{C}$ $\min ^{-1}$ ) and will be referred to as Rh11-c900, Rh5-c900, Rh2-c900, Rh5Ni-c900, Rh5-c9000.06M and Rh5-c900-0.1M. The reduced and spent samples will be named by replacing -c900 by -red or -used, respectively, i.e. Rh5-red or Rh5-used.

\subsection{Characterization techniques}

SEM/EDS analyses were performed by using an EVO 50 Series Instrument (LEO ZEISS) equipped with an INCAEnergy 350 EDS micro analysis system and INCASmartMap to image the spatial variation of elements in a sample (Oxford Instruments Analytical). An accelerating voltage of $20 \mathrm{kV}$ was applied with a spectra collection time of $60 \mathrm{~s}$, point and area measurements were performed in around 10-15 regions of interest. Secondary electron and backscattered electron images were collected. Wide regions were spanned to provide a well representative map of the catalysts, namely analyses were performed in struts of different geometry (tips, plate zones and arms connecting plate zones) placed along the foam cylinder surface. $\mathrm{Mg} / \mathrm{Rh}$ atomic ratios in the coating were estimated from EDS analyses, using standardless quantification. The contribution of the $\mathrm{Al}$ coming from the support makes it difficult to calculate $\mathrm{Mg} / \mathrm{Al}$ or $\mathrm{Rh} / \mathrm{Al}$ ratio values in the electrosynthesised solids, thus the amount of $\mathrm{Al}$ in the coating was only qualitatively estimated.

FEG-SEM analyses were performed by using a Zeiss LEO Gemini 1530 equipped with an Everhart-Thornley (E-T) secondary electron detector and a Scintillator BSE detector - KE Developments CENTAURUS. The accelerating voltages were 5 or $10 \mathrm{kV}$. Particle size distributions were obtained by the Image $\mathbf{J}$ software, at least 300 particles were analysed.

XANES profiles at the $\mathrm{Rh}-\mathrm{L}_{3}$ edge were collected on beamline ID21 at the European Synchrotron Radiation Facility (ESRF, Grenoble F) [56]. The storage ring operating conditions were $6 \mathrm{GeV}$ electron energy with $200 \mathrm{~mA}$ electron current and 7/8 multibunch operating mode. 
For these experiments a Si (111) double-crystal monochromator was used, having an energy resolution of $10^{-4}(\Delta \mathrm{E} / \mathrm{E})$.

A metallic $\mathrm{Rh}$ reference foil $(0.75 \mu \mathrm{m})$ was used to provide an accurate energy calibration for all the spectra (first inflection point of the Rh- $\mathrm{L}_{3}$ edge set at $3004.0 \mathrm{eV}$ [57]). For all XANES measurements, reference compounds and actual catalysts spectra were recorded with the sample positioned at $62^{\circ}$ with respect to the incoming beam. The fluorescence was recorded as a function of the incident X-ray energy at an angle of $49^{\circ}$ with respect to the sample. XANES spectra were collected from $\sim 35 \mathrm{eV}$ below to $\sim 130 \mathrm{eV}$ above the Rh-L 3 edge $(2970 \mathrm{eV}-3135$ $\mathrm{eV}$ ), with $0.25 \mathrm{eV}$ steps for the entire measured region. A $100 \mathrm{~ms}$ integration time was used for each energy resulting in a measuring time of $\sim 1$ min per XANES spectrum. 20-30 repeats were recorded to acquire noise-free spectra.

To obtain reference spectra, appropriate amounts of $\mathrm{Rh}$ model compounds were mixed with boron nitride, resulting in a weight percentage of $2 \%$ of the model compound to limit selfabsorption. Each mixture was compressed into a pellet and placed in a sample holder. To avoid contributions of possible heterogeneities during mixing, measurements were performed with an unfocused beam using a $200 \mu \mathrm{m}$ pinhole. Where needed (low Rh content in pellet) no pinhole was used resulting in a beam size of $\sim 500 \mu \mathrm{m}^{2}$. The fluorescence was recorded using a photodiode or a silicon drift diode (Bruker) (depending on the count rate).

For the measurements of the actual catalysts the beam size was reduced to $0.22 \times 0.85 \mu \mathrm{m}^{2}$ by using zone plate optics. Foam cylinders were embedded in a resin (Technovit 4006, Heraus Kulzer) and cut; finally polished cross-sections of the struts were analysed. The thickness of the embedded samples prevented transmission measurements thus allowing only monitoring of the fluorescence intensity as a function of the excitation energy. For this purpose a silicon drift diode was used. Prior to XANES measurements $\mu$ XRF maps were collected using the same setup and detector previously described with a step size of down to $0.5 \mu \mathrm{m}$. A primary excitation 
energy of $3008 \mathrm{eV}$ was employed in order to obtain a good XRF intensity for Rh present in the layer. These maps were used to locate interesting spots inside the Rh layer at which XANES spectra were recorded. In all maps a measuring time of $100 \mathrm{~ms}$ per pixel was used.

For all the XANES spectra, the normalization was performed by means of the software package ATHENA [58]. An edge-step normalization was performed by linear pre-edge subtraction and by regression of a (in general) quadratic polynomial beyond the edge [58]. If a silicon drift detector was used for the collection of XANES spectra, the recorded XRF spectra were evaluated using the PyMCA software package [59]. The fitted Rh intensity (sum of all Rh-L lines) was then plotted as a function of the excitation energy resulting in a (fluorescence mode) XANES spectrum. Analysis was performed by linear combination fitting of unknown spectra with spectra of known $\mathrm{Rh}$ reference compounds.

\subsection{Catalytic tests}

A quartz reactor (i.d. $10.0 \mathrm{~mm}$ ) was placed in an electrical oven and was loaded with two foam cylinders, which are located in the isothermal zone of the oven. The foams were made to fit well with the diameter of the reactor in order to minimize by-pass phenomena. In situ reduction was performed by an equimolar $\mathrm{H}_{2} / \mathrm{N}_{2}$ mixture $\left(7.0 \mathrm{~L} \mathrm{~h}^{-1}\right)$ for $2 \mathrm{~h}$ at $750{ }^{\circ} \mathrm{C}$ prior to the catalytic tests. The temperature at the inlet of the bed was monitored by a chromel alumel thermocouple placed inside a quartz wire. Reactant gases were supplied from individual cylinders and gas flow rates were measured with mass flow controllers, being mixed before entering in the quartz reactor. GHSV values and the composition of the gas mixture were varied as follow: GHSV = $11,500,15,250,38,700$ and $63,300 \mathrm{~h}^{-1}$ (calculated on the total volume of the foam support at STP conditions) and $\mathrm{CH}_{4} / \mathrm{O}_{2} / \mathrm{He}=2 / 1 / 20$ or $2 / 1 / 4 \mathrm{v} / \mathrm{v}$. Reaction products were analysed online, after water condensation, by a Perkin Elmer Autosystem XL gas chromatograph, equipped with two thermal conductivity detectors (TCD) and two Carbosphere columns using He as carrier gas for the $\mathrm{CH}_{4}, \mathrm{O}_{2}, \mathrm{CO}$, and $\mathrm{CO}_{2}$ analyses, and $\mathrm{N}_{2}$ for the $\mathrm{H}_{2}$ analysis. $\mathrm{CH}_{4}$ and $\mathrm{O}_{2}$ 
conversions and the selectivity in $\mathrm{H}_{2}$ and $\mathrm{CO}$ were calculated according to the previously reported formulas [60]. Oxygen conversion was completed in all the experiments.

\section{Results and Discussion}

\subsection{Effect of Rh content}

\subsubsection{SEM/EDS analyses}

Selected SEM images taken across the samples after electrosynthesis with the three different solutions $\mathrm{Rh} / \mathrm{Mg} / \mathrm{Al}=11 / 70 / 19,5 / 70 / 25$ and $2 / 70 / 28$ a.r. \% are displayed in figure 1 . The composition of the electrolytic solution does not alter the typical features of electrosynthesised materials [48]. The foam surface is almost entirely covered by a solid constituted of spherical nanoparticles and platelets, only some uncoated struts being identified. Preferential precipitation occurs on the tips resulting in a film of 5-15 $\mu \mathrm{m}$, and potassium deposits together with the expected elements.

When a thin film is deposited $(2-6 \mu \mathrm{m})$, the $\mathrm{Rh} / \mathrm{Mg} / \mathrm{Al}$ a.r. \% in the coating and the electrolytic solution are-is quite similar for all samples (Table 1). For thicker films the concentration of Rh and $\mathrm{Al}$ in the film increases as the synthesis proceeds, forming an outer layer with different composition. Namely the sequential precipitation of layers of different composition previously observed for Rh11-HT [48] also occurs in Rh5-HT and Rh2-HT samples; although next to these similarities some differences among samples are found in film thickness and composition. The $\mathrm{Rh}$ and $\mathrm{Al}$ content in the outer film depends on their Rh concentration in the correlates with the electrolytic solution composition (Table 1), for instance-the higher Rh content in the solution the higher Rh content in the solid, and it seems that the outer layer is not as abundant in Rh2$\mathrm{HT}$ as in Rh11-HT. The preferential precipitation of Al and Rh may be due to a decrease of the $\mathrm{pH}$ in the vicinity of the support when thick films deposit, because of an increase of the 
electrical resistance in the solid and/or to a mass transfer limited step of the electroactive species.

The thickness, compactness, and chemical composition of the precursor film determine the properties of the coating after calcination at $900{ }^{\circ} \mathrm{C}$ for $12 \mathrm{~h}$. SEM images of coated foams after calcination are displayed in figure 2. Likewise for Rh11-c900 sample [48], Al-rich layers identified in the electrosynthesised Rh5-HT and Rh2-HT samples develop a high number of cracks and the solid easily detach during calcination. In some cases it is possible to observe alumina needles. On the other hand, Mg-rich coatings or those whose composition is closer to the expected one are better adhered and more stable after calcination at high temperature. These catalytic coatings are constituted by flakes of globular or platelet-shaped nanoparticles; although some struts are crack free. As for Rh, its concentration in the catalytic layer measured by EDS correlates to the amount of Rh in the solution: Rh11-c900: 10-30 wt.\% > Rh5-c900: 5-15 wt.\% > Rh2-c900: 1-5 wt.\%.

The above commented features of calcined samples may be explained considering that the composition of the precipitated film determines the thermal decomposition pathway of the hydroxides and thermal-expansion coefficients of the formed oxides [61] as well as the chemical interaction between elements of coating and metallic support, such as previously reported for electrosynthesised catalysts [47]. For instance, higher amounts of $\mathrm{Mg}$ may favour the solid-state reaction between $\mathrm{Al}$ from the foam and $\mathrm{Mg}$ from the coating, increasing the stability of the film.

\subsection{2. $\mu X R F / X A N E S$ measurements}

$\mu \mathrm{XRF} / \mathrm{XANES}$ measurements were performed on cross-sections of selected embedded foams to characterise $\mathrm{Rh}$ species. To obtain representative results several regions were analysed, namely coated struts in the top, middle and bottom of foam cylinders. Selected representative 
data for the sample prepared with the $\mathrm{Rh} / \mathrm{Mg} / \mathrm{Al}=11 / 70 / 19$ a.r. \% solution at the different steps of the life cycle are displayed in figures 3 and 4 .

XRF maps (Fig. 3) were recorded at $0.5 \mu \mathrm{m}$ resolution of sectioned struts to select the points to be analysed by XANES (Fig. 4). The Fe-L distribution maps were used to represent the foam support, the Cr-L distribution is rather similar and thus not shown. To give information about the coating composition $\mathrm{Mg}-\mathrm{K}, \mathrm{Al}-\mathrm{K}$ and $\mathrm{Rh}-\mathrm{L}$ distribution maps are shown.

An estimation of each film thickness was obtained by fitting a gaussian to several $\mathrm{Mg}-\mathrm{K}$ and Rh-L line profiles across the film (See Fig.s S1, S2, S3, and S4, Supplementary information). The FWHM of these gaussians are given in Table 2; the mean value is an indication for the average layer thickness while its standard deviation is an indication for the variation in thickness.

Elemental distribution maps of cross-sections for Rh11-HT (see as an example Fig. 3a) indicate that $\mathrm{Mg}, \mathrm{Rh}$ and $\mathrm{Al}$ follow a similar distribution in regions of interest located in different areas of the foam surface. On the other hand, the film thickness depends on the inspected region; thicknesses range from 2 to $10 \mu \mathrm{m}$ with an average value of around $5 \mu \mathrm{m}$ for $\mathrm{Rh}$ and $4 \mu \mathrm{m}$ for $\mathrm{Mg}$ in the selected area displayed in figure 3. The thicker $\mathrm{Rh}$ than Mg layer may be explained considering that the outer layer mainly contains $\mathrm{Rh}$ and $\mathrm{Al}$ as previously observed by SEM/EDS. High resolution XRF maps (Fig. 4), confirmed that all the elements (i.e. $\mathrm{Rh}, \mathrm{Mg}$ and $\mathrm{Al}$ ) are intermixed but their concentration depend on the region of interest also in agreement with EDS. The high noise level of XANES spectra recorded on this sample, made it impossible to perform Linear Combination Fitting (LCF). However the position of the white-line at ca. $3007.0 \mathrm{eV}$ confirms that the coating contains $\mathrm{Rh}^{3+}$ species. These results agree with those recently published by some of us [48] and further confirm that the precipitation of $\mathrm{Rh}^{3+}$ rather than its reduction occurs during electrosynthesis. 
After calcination (Fig. 3b) the correlation between the distribution of $\mathrm{Rh}, \mathrm{Mg}$ and $\mathrm{Al}$ remains; however, $\mathrm{Rh}$ and $\mathrm{Mg}$ coating thickness are similar, around $4 \mu \mathrm{m}$ (Table $\underline{2}$ ). The interdiffusion of the species or the detachment of the outer layer during calcination may explain this behaviour. XRF maps of hollow struts once again confirm that the electrosynthesis takes place in both the outer and inner surface, increasing the surface available for catalytic tests [47]. Selected regions, corresponding to several concentrations of $\mathrm{Rh}$ in the layer, were examined by XANES (Table S1, Supplementary Information). Rh-L 3 XANES spectra (Fig. 4, point B1) display a white-line at $3007.0 \mathrm{eV}$ due to the electron transition from $2 \mathrm{p}_{3 / 2}$ to $4 \mathrm{~d}_{3 / 2}$ and $4 \mathrm{~d}_{5 / 2}$ and peaks at higher energies attributed to transitions to $\mathrm{pd}, \mathrm{df}$, $\mathrm{f}$ and $\mathrm{df}$ orbitals [60]. LCF revealed that, regardless the inspected region, $\mathrm{Rh}$ is present in a spinel structure forming a $\operatorname{Mg}\left(\mathrm{Rh}_{\mathrm{x}} \mathrm{Al}_{1}\right.$ х) $)_{2} \mathrm{O}_{4}$ solid solution rather than segregated as $\mathrm{Rh}_{2} \mathrm{O}_{3}$, which was detected in samples prepared by electrosynthesis using $\mathrm{KNO}_{3}$ as supporting electrolyte [47].

By decreasing the Rh loading in Rh5-c900 and Rh2-c900 samples (Table S2, Supplementary Information), elemental distributions and Rh speciation remain similar to those in Rh11-c900. $\mathrm{Rh}, \mathrm{Mg}$ and $\mathrm{Al}$ cover the foam surface and $\mathrm{Rh}^{3+}$ species are included in the $\mathrm{MgAl}_{2} \mathrm{O}_{4}$ spinel. The formation of the $\mathrm{Mg}\left(\mathrm{Rh}_{\mathrm{x}} \mathrm{Al}_{1-\mathrm{x}}\right)_{2} \mathrm{O}_{4}$ solid solution may prevent the sintering of $\mathrm{Rh}^{0}$ particles; however the $\mathrm{Rh}^{3+}$ to $\mathrm{Rh}^{0}$ reducibility decreases [47], since higher temperatures are required to perform the reduction. In order to obtain information about the reducibility of $\mathrm{Rh}$, the sample with the highest Rh loading was studied after the reduction treatment before catalytic tests, Rh11-red (Figs. 3c and 4 point C1). A less intense white-line at $3005.0 \mathrm{eV}$ due to the decrease of $4 \mathrm{~d}$ holes is expected for the reduced sample [63,64]. However, the white-line of Rh11-rid sample is composed of two overlapped peaks at 3005.0 and $3007.0 \mathrm{eV}$ (Fig. 4, point C1) due to the presence of both $\mathrm{Rh}^{0}$ and $\mathrm{Rh}^{3+}$ species in the coating. The amount of $\mathrm{Rh}^{0}$ species varies from 21 to $54 \%$ in the analysed points. Hence, the $\mathrm{Rh}^{3+}$ reduction is incomplete during the 
activation treatment in $\mathrm{H}_{2}$, although the oxidation of the metallic particles during the preparation of the samples may not be discarded.

\subsubsection{Catalytic activity}

Catalytic tests were performed feeding two $\mathrm{CH}_{4} / \mathrm{O}_{2} / \mathrm{He}$ mixtures $(2 / 1 / 20$ and $2 / 1 / 4 \mathrm{v} / \mathrm{v})$ to the reactor, with the following GHSV values: $63,300,38,700,15,250$, and 11,500 $\mathrm{h}^{-1}$. Initial reaction conditions, namely $\mathrm{CH}_{4} / \mathrm{O}_{2} / \mathrm{He}=2 / 1 / 20 \mathrm{v} / \mathrm{v}$ and $63,300 \mathrm{~h}^{-1}$, were set at the end of every test to evaluate possible deactivation/activation (control test). The evolution of $\mathrm{CH}_{4}$ conversion and selectivities in $\mathrm{CO}$ and $\mathrm{H}_{2}$ with time-on-stream (TOS) by modifying reaction conditions for the three catalysts are summarized in figures 5 and 6.

In the case of Rh11-c900, feeding the diluted reaction gas mixture at $63,300 \mathrm{~h}^{-1}$ the $\mathrm{CH}_{4}$ conversion is around $82 \%$ during the first $120 \mathrm{~min}$ of TOS. Conversely, Rh5-c900 and Rh2c900 catalysts activated with TOS and $\mathrm{CH}_{4}$ conversion is related to the $\mathrm{Rh}$ content within the coating. After $120 \mathrm{~min}$ of TOS, conversion increases from 70 to $76 \%$ for Rh5-c900 and from 55 to $60 \%$ for Rh2-c900. The main reaction products with Rh11-c900 and Rh5-c900 catalysts are $\mathrm{CO}$ and $\mathrm{H}_{2}$, although the syngas selectivity is lower for the latter catalyst. On the other hand, the Rh2-c900 sample shows a higher selectivity in $\mathrm{CO}$ than in $\mathrm{H}_{2}$ at the beginning of tests, while the differences were smoothed with TOS.

Catalytic performances improve as the GHSV values decreased to 38,700 and $15,250 \mathrm{~h}^{-1}$, in agreement with the behaviour previously reported by some of us for this type of catalysts [44,45]. Quite stable performances are achieved with the Rh11-c900 catalyst, regardless of the total flow rate, with a conversion above $90 \%$ at $15,250 \mathrm{~h}^{-1}$. On the contrary, Rh5-c900 and Rh2-c900 samples slightly deactivate with TOS (ca. $1 \%$ loss in $\mathrm{CH}_{4}$ conversion); the former only at $15,250 \mathrm{~h}^{-1}$, while the latter both at 38,700 and $15,250 \mathrm{~h}^{-1}$. 
The control tests evidenced that runs at $38,700 \mathrm{~h}^{-1}$ and $15,250 \mathrm{~h}^{-1}$ do not largely modify the Rh11-c900 and Rh5-c900 catalysts; nevertheless the Rh2-c900 sample increased conversion and selectivities after both catalytic tests.

To explain the catalytic behaviour (namely, activation with TOS, activity and stability of the catalysts) the properties of the coating, thickness and composition, and the reactions taking place in the catalytic bed have to be considered. $\mathrm{CH}_{4}$ is converted by exothermic reactions, total or partial oxidation, and by the endothermic steam reforming. On the whole, in diluted reaction conditions, the higher the rhodium loading and coating thickness the better the performances are. Considering that oxidation reactions are fast and controlled by $\mathrm{O}_{2}$ mass-transfer [27], the differences in conversion and selectivity may be related to the ability of the catalyst to perform the consecutive SR process. A small amount of exposed $\mathrm{Rh}^{0}$ active sites due to low $\mathrm{Rh}$ loading in the coating, the formation of large particles or the presence of unreduced $\mathrm{Rh}^{3+}$ species, may decrease the $\mathrm{CH}_{4}$ conversion by SR. For instance, in Rh5-c900 and Rh2-c900 catalysts, the activation observed with TOS may indicate that the presence of some hardly reducible Rh3+ $\underline{\text { species decreases their initial activity, but the reaction conditions may help to reduce them and }}$ enhance the performances. The SR produces a large amount of $\mathrm{H}_{2}$, thus if its contribution lowers, not only the $\mathrm{CH}_{4}$ conversion, but also the selectivity in $\mathrm{H}_{2}$ decreases, as observed for the Rh2-c900 sample. At lower GHSV runs, the improvement in the conversion is related to the lower $\mathrm{CH}_{4}$ flow, while the contribution of the heat generated may explain the differences in stability. The heat developed by exothermic reactions contributes to the catalytic activity and it depends on the total flow rate. In tests at $38,700 \mathrm{~h}^{-1}$ and $15,250 \mathrm{~h}^{-1}$ is reduced, hence it will not help to keep the catalyst active with TOS.

Feeding more concentrated gas mixtures the trend of conversion and selectivity values changes. Rh5-c900 is the most active and selective catalyst; the largest difference with Rh2-c900 and Rh11-c900 samples were observed at $15,250 \mathrm{~h}^{-1}$. The temperature increase due to exothermic 
oxidation reactions is higher in concentrated tests; however, both the amount of $\mathrm{CH}_{4}$ to be converted and the partial pressure of the reactants are higher, having an effect on both conversion and stability. On one hand the temperature increase promotes the catalytic activity, on the other hand it favours the sintering of metallic particles. It is noteworthy that all catalysts, regardless of their composition, lose activity with TOS, around $2 \%$ in $\mathrm{CH}_{4}$ conversion, as confirmed by the control test. However, it appears that the deactivation is partially reversible, namely the catalyst steadily recovered the original activity with TOS under the control test. Since the sintering is not reversible but the oxidation is, the latter phenomena may explain the loss of activity. Although the formation of carbon and its gasification with TOS could also occur.

\subsubsection{Characterization of spent samples}

The coating is modified during catalytic tests due to the gas flow rate and the temperatures inside the catalytic bed. A general behaviour is observed, for all three catalysts, depending on the composition and morphology of the fresh catalyst [48]. Selected SEM images of the Rh5c900 catalyst cylinders placed at the beginning of the catalyst bed are displayed in figure 7 as an example. Partial detachment occurs in the outer film enriched in $\mathrm{Al}$ and $\mathrm{Rh}$ (Fig. 7a), and mostly in the foam placed at the entrance of the catalytic bed. On the contrary, the film in close contact with the foam surface, formed by plate-like or globular particles remains well adhered. Whenever the amount of the cracks increases the characteristic $\mathrm{Al}_{2} \mathrm{O}_{3}$ needles are observed (not shown).

Carbon on the catalyst surface was detected by EDS, mainly in the foam placed at the outlet of the catalytic bed, in agreement with previous studies that revealed that the absence of gas-phase oxygen favours the formation of carbonaceous deposits [15]. High resolution FEG-SEM images confirm that both patches (Fig. 7b) and nanotubes of carbon (ca. $50 \mathrm{~nm}$ diameter) (Fig. 7c) are formed on the catalyst surface. 
The Rh particle size distribution was studied by means of FEG-SEM backscattering images. Images of outer layer of spent catalysts at different $\mathrm{Rh}$ loadings, taken from cylinders placed at the top of the catalytic bed, and particle size distributions obtained by analysing representative regions of interest are shown in figure 8 . A broad particle size distribution $(20-200 \mathrm{~nm})$ was measured in Rh11-used sample (Fig.s $8 \mathrm{a}$ and $\mathrm{a}^{*}$ ). The frequency of particles in the 20-100 nm range increases for Rh5-used sample (Fig.s $8 b$ and $b^{*}$ ), although some irregular shaped and large agglomerates of particles are still found. Regarding the inspection of films of different thickness, for both Rh5-used and Rh11-used catalysts, the largest metallic particles are predominantly located in the thicker layers, while smaller and more dispersed particles are observed in thinner layers corresponding to Mg-rich coatings and in the middle of needles and plates. The particle size largely decreases for Rh2-c900 spent sample (Fig.s 8c and 8c*). A narrow particle size distribution in the 4-40 $\mathrm{nm}$ range is measured, even in some regions where the Rh wt.\% was high. Hence, the Rh content in the film, which is related to the concentration of $\mathrm{Rh}$ in the electrolytic solution and the film thickness, determines the $\mathrm{Rh}$ particle size distribution.

For Rh11 used samples the two foams cylinders loaded in the catalytic reactor were analysed by $\mu \mathrm{XRF} / \mathrm{XANES}$. In agreement with SEM/EDS characterization, $\mathrm{Rh}, \mathrm{Mg}$ and $\mathrm{Al}$ elemental distribution maps indicate that the film in close contact with the foam surface is well adhered (Fig. 3d). The measured thickness is comparable to the calcined sample, although there are some points wherein the Rh thickness is larger than the Mg thickness (Table 2 and Fig. S4). The white-line in XANES spectra (Fig. 4, point D1) is actually composed of the two overlapped peaks already identified in the reduced sample, due to the coexistence of both $\mathrm{Rh}^{0}$ and $\mathrm{Rh}^{3+}$ in the used samples. LCF (Table S2, Supplementary Information) reveals that the amount of $\mathrm{Rh}^{0}$ is lower in the foam placed at the inlet $\left(10-35 \%\right.$ of $\left.\mathrm{Rh}^{0}\right)$ than at the outlet of the catalytic bed (ca. $40 \%$ of $\mathrm{Rh}^{0}$ ), these values differ from those obtained for the Rh11-red sample (21-54\% 
$\mathrm{Rh}^{0}$ ). It is important to underline that all measurements were performed ex-situ, therefore as previously commented for the $\mathrm{Rh} 11$-red sample, the oxidation of $\mathrm{Rh}^{0}$ by exposure to the air cannot be discarded. However, the shutdown of the reactor was performed as in ref [39], shutting $\mathrm{CH}_{4}$ and oxygen simultaneously, avoiding modifications in the catalyst. From our results it appears that, despite the high temperatures reached in the catalytic bed, some $\mathrm{Rh}^{3+}$ species are still present. The consumption rate of $\mathrm{O}_{2}$ is mass transfer limited [27], thus the oxidation of $\mathrm{CH}_{4}$ is a fast reaction. However, the $\mathrm{CH}_{4}$ molecule firstly has to be activated by the metallic particles forming $-\mathrm{C}^{*}$. Thus if the number of active sites is not large enough to activate $\mathrm{CH}_{4}$, as in some of these structured catalysts, $\mathrm{O}_{2}$ may foster the $\mathrm{Rh}^{0}$ oxidation.

In summary, the size of the metallic particles is reduced by decreasing the concentration of Rh species in the electrolytic solution. However the lower amount of active sites is responsible of a lower catalytic activity and the composition of the solid is not controlled yet.

\subsection{Effect of total $\mathrm{Rh} / \mathrm{Mg} / \mathrm{Al}$ concentration}

In the electrosynthesis a limiting step to achieve the desired composition and thickness may be the mass transfer from the bulk of the solution to the vicinity of the support [65], as observed in the reduction of nitrate [50]. To enhance the nitrate and cation mass transfer, the total concentration of $\mathrm{Rh}, \mathrm{Mg}$ and $\mathrm{Al}$ nitrates was increased from $0.03 \mathrm{M}$ to $0.06 \mathrm{M}$ and $0.1 \mathrm{M}$, while the $\mathrm{Rh} / \mathrm{Mg} / \mathrm{Al}$ a.r. \% was kept constant at 5/70/25. Due to the higher concentration of electroactive nitrate species a higher cathodic current was measured (results not shown). Considering that only Faraday's current flows through the system, it may be stated that a larger amount of nitrates is reduced generating a higher amount of hydroxyl species; however, the contribution of water electrolysis and oxygen reduction to the raise of the $\mathrm{pH}$ may not be discarded $[48,50,66]$. 
As a result of the above commented effects, and taking into account the key role of the $\mathrm{pH}$ in the deposition of this type of materials, an increase in the amount of deposited solid and in the coating homogeneity are obtained with the $0.06 \mathrm{M}$ solution (Fig. 9a). The shape of individual particles, globular and platelets, is not largely altered although they seem to be slightly smaller leading to a more compact film and with less cracks, probably on account of a higher supersaturation. Film thicknesses are around 15-20 $\mu \mathrm{m}$ in the most exposed areas, while in plate zones they are around $5 \mu \mathrm{m}$. As for the composition, atomic ratio values close to the expected one $(\mathrm{Rh} / \mathrm{Mg} / \mathrm{Al}=4 / 68 / 28$ a.r. \%) are measured in some parts of the foam. On the other hand, when thicker layers are observed, the sequential precipitation still takes place $(\mathrm{Rh} / \mathrm{Mg} / \mathrm{Al}=$ $10 / 39 / 51$ and 14/26/60 a.r. \%).

A further increase in the concentration of the cations to $0.1 \mathrm{M}$ has a negative effect on the coating properties (results not shown). A large amount of solid precipitates, forming some crusts; however, it easily detached and the deposition was not controlled as previously observed for $\mathrm{Mg}(\mathrm{OH})_{2}$ coatings [54]. Not only the composition of the solid differs from the expected one, but also the formation of rhodium metallic particles takes place.

The enhanced coverage in the precursor in terms of thickness and homogeneity obtained with the $0.06 \mathrm{M}$ instead of the $0.03 \mathrm{M}$ solution, led to an improvement in the film features of the calcined sample. However, it was not possible to completely avoid the formation of cracks related to differences in thermal expansion coefficients and film shrinkage, consequently the detachment of the outer layer occurred (Fig. 9b). An average Rh concentration of 5-15 wt.\% was measured by EDS analyses.

A comparison between the $\mathrm{CH}_{4}$ conversion obtained with the catalyst prepared with the $0.03 \mathrm{M}$ and $0.06 \mathrm{M}$ solutions is summarized in figure 10 . The values in conversion of $\mathrm{CH}_{4}$ and syngas selectivity (not shown) overcome those of the Rh5-c900 sample in all the reaction conditions. In contrast, the catalyst stability with TOS only improves during diluted tests. Furthermore, it 
is noteworthy that the activation with TOS under the two initial reaction conditions took place, suggesting a similar $\mathrm{Rh}$ speciation.

The characterization of the Rh5-c900-0.06M sample after catalytic tests reveals modifications of the film similar to those reported above for Rh5-c900. While Mg-rich layers are stable and almost crack-free, the detachment of the Rh and Al-rich outer layer continued during catalytic tests. A particle size distribution in the 10 to $80 \mathrm{~nm}$ range is measured in the used sample with a $24 \mathrm{~nm}$ mean value (Fig. 11a). The largest Rh metallic particles are usually present in the thicker layers (Fig. 11c) while small and well distributed particles locate in the film in close contact with the metallic support and in the middle of $\mathrm{Al}_{2} \mathrm{O}_{3}$ needles (Fig. 11b). The latter $\mathrm{Rh}$ particles suggest that the needles are not only related to $\mathrm{Al}_{2} \mathrm{O}_{3}$ formed by oxidation from the FeCrAlloy support, but to an electrodeposited $\mathrm{Al}_{2} \mathrm{O}_{3}$ or $\mathrm{MgAl}_{2} \mathrm{O}_{4}$.

Hence, in the Rh5-c900-0.06M catalyst a higher amount of dispersed Rh particles in a thicker and more homogeneous coating layer in comparison with Rh5-c900 sample, improve the performances however the deactivation by feeding concentrated gas mixtures may not be avoided.

\subsection{Bimetallic RhNi catalyst}

The inclusion of a second metal such as $\mathrm{Ni}$ would increase the number of active sites contributing to the conversion of $\mathrm{CH}_{4}$. However, the electrosynthesis of a HT with four different cations is challenging. The partial replacement of $\mathrm{Mg}$ by $\mathrm{Ni}$ in the electrolytic solution $(\mathrm{Rh} / \mathrm{Ni} / \mathrm{Mg} / \mathrm{Al}=5 / 15 / 55 / 25$ a.r. \%) improves the coverage degree of the foam surface; the lower $\mathrm{pH}$ required to precipitate a $\mathrm{Ni}$ - than $\mathrm{Mg}$-containing $\mathrm{HT}$ may explain this behaviour [42]. But still several layers of solid are identified in SEM images, whose composition seems to be related with the precipitation $\mathrm{pH}$ of the individual hydroxides. The deposition of $\mathrm{Mg}$ and $\mathrm{Ni}$ is low in very thin layers, the $\mathrm{Mg} / \mathrm{Ni}$ value is close to the expected one, i.e. 3.7, for intermediate 
thicknesses and then it decreases to ca. 2.5-1.0 for thicker layers. Likewise the above commented samples, $\mathrm{Al}$ and $\mathrm{Rh}$ contents are larger in the outer layer (for instance $\mathrm{Rh} / \mathrm{Ni} / \mathrm{Mg} / \mathrm{Al}$ $=10 / 6 / 9 / 60$ a.r. \%). After calcination (Fig. 12a), the same general trend previously commented for the $\mathrm{Rh} / \mathrm{Mg} / \mathrm{Al}$ samples is observed, although it appears that the film is more stable, i.e. the detachment of the film is less evident. The $\mathrm{Ni}$ and $\mathrm{Rh}$ contents are $7-15$ and $3-15 \mathrm{wt} . \%$, respectively.

Elemental XRF maps of some foam struts confirm that the distribution of $\mathrm{Ni}$ in the Rh5Ni-c900 catalyst correlates with those of $\mathrm{Mg}, \mathrm{Rh}$ and $\mathrm{Al}$ (Fig. 12b). It was not possible to fit the spectra; but the $\mathrm{Rh}-\mathrm{L}_{3}$ edge (inflection points) suggests that there are no differences in the Rh speciation in comparison to the above commented $\mathrm{Rh} / \mathrm{Mg} / \mathrm{Al}$ samples.

On the other hand, the partial replacement of $\mathrm{Mg}$ by $\mathrm{Ni}$ largely improves the catalytic performances. The bimetallic Rh5Ni-c900 catalyst reaches conversion values around or above $90 \%$ in all tests (Fig. 10), and consequently both the selectivity in $\mathrm{CO}$ and $\mathrm{H}_{2}$ are above $95 \%$. Despite the high activity, the catalyst steadily deactivates under both concentrated and diluted reaction conditions, mainly during the test at lowest GHSV, wherein a lower amount of heat is developed. The oxidation of nickel species may explain this behaviour, although the detachment of some parts of the coating observed by SEM imaging, may be not be excluded. An electrosynthesised foam containing only $\mathrm{Ni}$ as active phase was not active [43], hence it may be stated that, similar to conventional pelletized samples, Rh helps to keep Ni in the reduced and consequently active [55] state, although its oxidation or other type of deactivation is not fully avoided.

\section{Conclusions}

The tailoring of Rh content and concentration of metals in the electrolytic solution as well as the formation of bimetallic RhNi particles may lead to catalysts with smaller, more dispersed 
and stabilized $\mathrm{Rh}$ metallic particles in the coating and achieving a higher activity, although the stability should still be improved.

The $\mathrm{Rh}$ content in the precipitated solid, present as hardly reducible $\mathrm{Mg}\left(\mathrm{Rh}_{1-\mathrm{x}} \mathrm{Al}_{\mathrm{x}}\right)_{2} \mathrm{O}_{4}$, correlated with the $\mathrm{Rh}$ loading in the solution; hence $\mathrm{Rh}$ particle size decreased by modifying the $\mathrm{Rh} / \mathrm{Mg} / \mathrm{Al}$ in the electrolytic solution from $11 / 70 / 19$ to $5 / 70 / 25$ and $2 / 70 / 28$ a.r.\% $(0.03 \mathrm{M}$ total concentration). However, the precipitation of a film enriched in $\mathrm{Al}$ and $\mathrm{Rh}$ (outer film) after the deposition of a solid with a composition close to the expected one, generated differences in particle size and dispersion with the coating thickness. For these samples, the catalytic activity was mainly related to the $\mathrm{Rh}$ content rather than to the metallic particle size and rhodium species suffer from reduction and oxidation with time-on-stream depending on the dilution degree of the $\mathrm{CH}_{4} / \mathrm{O}_{2} / \mathrm{He}$ gas mixture.

The total metal concentration was the main parameter to be modified to precipitate thicker films with a higher amount of active sites, without altering the growth and sintering behaviour of rhodium particles, and therefore to achieve a better activity. While the addition of $\mathrm{Ni}$ to the electrolytic solution contributed to the catalytic activity but the catalyst steadily deactivated.

Further improvements are required to control the composition of the deposited solid, which determines not only the metallic particle size but also the adhesion of the film during calcination and catalytic tests.

\section{Acknowledgements}

The Authors acknowledge M. Salome for helping during the $\mu$ XRF/XANES experiments at ID21 Beamline of the ESRF, the Department of Structural Characterization of CNR-IMM of Bologna for the access to the FEG-SEM facility and Dr F. Ospitali for the scientific support. Thanks are due to Farrel Lytle database for providing the necessary Rh metal spectrum 
(rhfoil.a99 in http://ixs.iit.edu/data/Farrel Lytle data/). The financial support from the Ministero per l'Istruzione, l'Università e la Ricerca (MIUR, Roma, Italy) and the University of Bologna (FARB program) is gratefully acknowledged.

\section{References}

[1] L.E. Basini, A. Guarinoni, Ind. Eng. Chem. Res. 52 (2013) 17023-17037.

[2] B. Enger, R. Lødeng, A. Holmen Appl. Catal. A 346 (2008) 1-27.

[3] R. Horn, K.A. Williams, N.J. Degenstein, A. Bitsch-Larsen, D. Dalle Nogare, S.A. Tupy, L.D. Schmidt, J. Catal. 249 (2007) 380-393.

[4] D. Dalle Nogare, N.J. Degenstein, R. Horn, P. Canu, L.D. Schmidt, J. Catal. 258 (2008) $131-142$.

[5] A. Donazzi, M. Maestri, B.C. Michel, A. Beretta, P. Forzatti, G. Groppi, E. Tronconi, L.D. Schmidt, D.G. Vlachos, J. Catal. 275 (2010) 270-279.

[6] M. Maestri, D. Livio, A. Beretta, G. Groppi, Ind. Eng. Chem. Res. 53 (2014) 10914-10928.

[7] C.T. Goralski Jr., R.P. O'Connor, L.D. Schmidt, Chem. Eng. Sci. 55 (2000) 1357-1370.

[8] I. Tavazzi, A. Beretta, G. Groppi, M. Maestri, E. Tronconi, P. Forzatti, Catal. Today 129 (2007) 372-379.

[9] A. Beretta, G. Groppi, M. Lualdi, I. Tavazzi, P. Forzatti, Ind. Eng. Chem. Res. 48 (2009) $3825-3836$.

[10] E. Tronconi, G. Groppi, C. Visconti, Curr. Opin. Chem. Eng. 5 (2014) 55-67.

[11] K. Liu, G.D. Deluga, A. Bitsch-Larsen, L.D. Schmidt, L. Zhang in Hydrogen and Syngas Production and Purification Technologies, K. Liu, C. Song, V. Subramani (Eds.) John Wiley \& Sons, Inc., Hoboken, New Jersey, pp 127-155.

[12] T. Liu, C. Snyder, G. Veser, Ind. Eng. Chem. Res. 46 (2007) 9045-9052.

[13] S. Cimino, L. Lisi, G. Russo, R. Torbati, Catal. Today 154 (2010) 283-292. 
[14] A. Donazzi, D. Livio, C. Diehm, A. Beretta, G. Groppi, P. Forzatti, Appl. Catal. A: Gen. 469 (2014) 52-64.

[15] O. Korup, C.F. Goldsmith, G. Weinberg, M. Geske, T. Kandemir, R. Schlögl, R. Horn, J. Catal. 297 (2013) 1-16.

[16] A. Donazzi, B.C. Michael, L.D. Schmidt, J. Catal. 260 (2008) 270-275.

[17] G. Landi, P.S. Barbato, S. Cimino, L. Lisi, G. Russo, Catal. Today 155 (2010) 27-34.

[18] L. Coleman, E. Croiset, W. Epling, M. Fowler, R. Hudgins, Catal. Lett. 128 (2009) $144-153$.

[19] S. Cimino, L. Lisi, G. Mancino, M. Musiani, L. Vázquez-Gómez, E. Verlato, Int. J. Hydrogen Energy 37 (2012) 17040-17051.

[20] H. Jung, W.L. Yoon, H. Lee, J.S. Park, J.S. Shin, H. Lab, J.D. Lee, J. Power Sources 124 (2003) 76-80.

[21] A. Shamsi, J.J. Spivey, Ind. Eng. Chem. Res. 44 (2005) 7298-7305.

[22] L. Bobrova, N. Vernikovskaya, V. Sadykov, Catal. Today 144 (2009) 185-200.

[23] E. Verlato, S. Barison, S. Cimino, F. Dergal, L. Lisi, G. Mancino, M. Musiani, L. VázquezGómez, Int. J. Hydrogen Energy 39 (2014) 11473-11485.

[24] K.L. Hohn, L. D. Schmidt, Appl. Catal. A: Gen. 211 (2001) 53-68.

[25] M. Maestri, A. Beretta, G. Groppi, E. Tronconi, P. Forzatti, Catal. Today 105 (2005) 709717.

[26] A. Beretta, A. Donazzi, D. Livio, M. Maestri, G. Groppi, E. Tronconi, P. Forzatti, Catalysis Today 171 (2011) 79-83.

[27] T. Maffei, S. Rebughini, G. Gentile, S. Lipp, A. Cuoci, M. Maestri, Chem. Ing. Tech. 86 (2014) 1099-1106.

[28] D. Livio, A. Donazzi, A. Beretta, G. Groppi, P. Forzatti, Top. Catal. 54 (2011) 866-872. ha formattato: Italiano (Italia)

ha formattato: Italiano (Italia)

ha formattato: Italiano (Italia) ha formattato: Inglese (Regno Unito)

ha formattato: Inglese (Regno Unito) 
[29] J.E.P. Navalho, I. Frenzel, A. Loukou, J.M.C. Pereira, D. Trimis, J.C.F. Pereira, Int. J. Hydrogen Energy 38 (2013) 6989-7006.

[30] S. Ding, Y. Yang, Y. Jin, Y. Cheng, Ind. Eng. Chem. Res. 48 (2009) 2878-2885.

[31] S. Cimino, G. Landi, L. Lisi, G. Russo, Catal. Today 105 (2005) 718-723.

[32] C.J. Bell, C.A. Leclerc, Energy Fuels 21 (2007) 3548-3554.

[33] A.S. Bodke, S.S. Bharadwaj, L.D. Schmidt, J. Catal. 179 (1998) 138-149.

[34] M.J. Stutz, D. Poulikakos, Chem. Eng. Sci. 63 (2008) 1761-1770.

[35] V. Meille, Appl. Catal. A: Gen, 315 (2006) 1-17.

[36] A. Montebelli, C.G. Visconti, G. Groppi, E. Tronconi, C. Cristiani, C. Ferreira, S. Kohler, Catal. Sci. Technol. 4 (2014) 2846-2870.

[37] U. Zavyalova, F. Girgsdies, O. Korup, R. Horn, R. Schlögl, J. Phys. Chem. C 113 (2009) $17493-17501$

[38] A. Donazzi, D. Pagani, A. Lucotti, M. Tommasini, A. Beretta, G. Groppi, C. Castiglioni, P. Forzatti, Appl. Catal. A: Gen. 474 (2014) 149-158.

[39] R. Chakrabarti, J.S. Kruger, R.J. Hermann, S.D. Blass, L.D. Schmidt, Appl. Catal. A: Gen. 483 (2014) 97-102.

[40] J.-D. Grunwaldt, S. Hannemann, C.G. Schroer, A. Baiker, J. Phys. Chem. B 110 (2006) 8674-8680.

[41] F. Basile, P. Benito, G. Fornasari, A. Vaccari, Appl. Clay Sci. 48 (2010) 250-259.

[42] P. Benito, F. Basile, G. Fornasari, M. Monti, E. Scavetta, D. Tonelli, A. Vaccari, in New Strategies in Chemical Synthesis and Catalysis (Ed. B. Pignataro), Wiley-VCH, Weinheim, Germany, 2012, Chapter 6, pp201-217.

[43] F. Basile, P. Benito, G. Fornasari, M. Monti, E. Scavetta, D. Tonelli, A. Vaccari, Stud. Surf. Sci. Catal. 175 (2010) 51-58. ha formattato: Italiano (Italia)

ha formattato: Italiano (Italia)

ha formattato: Inglese (Regno Unito)

ha formattato: Inglese (Regno Unito)

ha formattato: Inglese (Regno Unito)

ha formattato: Italiano (Italia)

ha formattato: Italiano (Italia)

ha formattato: Italiano (Italia)

ha formattato: Italiano (Italia)

ha formattato: Italiano (Italia)

ha formattato: Italiano (Italia)

ha formattato: Olandese (Paesi Bassi)

ha formattato: Olandese (Paesi Bassi) 
[44] F. Basile, P. Benito, G. Fornasari, M. Monti, E. Scavetta, D. Tonelli, A. Vaccari, Catal. Today 157 (2010) 183-190.

[45] P. Benito, M. Monti, I. Bersani, F. Basile, G. Fornasari, E. Scavetta, D. Tonelli, A. Vaccari, Catal. Today 197 (2012) 162-169.

[46] M. Monti, P. Benito, F. Basile, G. Fornasari, M. Gazzano, E. Scavetta, D. Tonelli, A. Vaccari, Electrochim. Acta 108 (2013) 596-604.

[47] P. Benito, W. de Nolf, G. Nuyts, M. Monti, G. Fornasari, F. Basile, K. Janssens, F. Ospitali, E. Scavetta, D. Tonelli, A. Vaccari, ACS Catal. 4 (2014) 3779-3790.

[48] P. Benito, M. Monti, W. De Nolf, G. Nuyts, G. Janssen, G. Fornasari, E. Scavetta, F. Basile, K. Janssens, F. Ospitali, D. Tonelli, A. Vaccari, Catal. Today (2014) 246 (2015) 154-164.

[49] G.H.A. Therese, P.V. Kamath, Chem. Mater. 12 (2000) 1195-1204.

[50] M. Nobial, O. Devos, O.R. Mattos, B. Tribollet, J. Electroanal. Chem. 600 (2007) 87-94. [51] I. Reyero, I. Velasco, O. Sanz, M. Montes, G. Arzamendia, L.M. Gandía, Catal. Today 216 (2013) 211-219.

[52] I. Zhitomirsky, Adv. Coll. Interf. Sci. 97 (2002) 279-317.

[53] G.H.A. Therese, P.V. Kamath, Chem. Mater. 11 (1999) 3561-3564.

[54] M. Dinamani, P.V. Kamath, J. Appl. Electrochem. 34 (2004) 899-902.

[55] F. Basile, G. Fornasari, F. Trifirò, A. Vaccari, Catal. Today 64 (2001) 21-30.

[56] M. Salome, M. Cotte, R. Baker, R. Barrett, N. Benseny-Cases, G. Berruyer, D. Bugnazet, H. Castillo-Michel, C. Cornu, B. Fayard, R. Gagliardini, E. az nd Hino, J. Morse, E. Papillon, E. Pouyet, C. Rivard, V.A. Sole, J. Susini, G. Veronesi, 11th International Conference on Synchrotron Radiation Instrumentation (SRI 2012), Dirac House, Temple Back, Bristol BS1 6BE, England, (2013).

ha formattato: Inglese (Regno Unito)

ha formattato: Inglese (Regno Unito) ha formattato: Inglese (Regno Unito)

ha formattato: Italiano (Italia)

ha formattato: Italiano (Italia)

ha formattato: Italiano (Italia)

ha formattato: Italiano (Italia) 
[57] W.H. McMaster, N.K. Del Grande, J.H. Mallett, J.H. Hubbell, Compilation of Xray Cross Sections, Lawrence Radiation Laboratory UCRL-50174 sec II, Rev. 1 (1969).

[58] B. Ravel, M. Newville, J. Synchrotron Radiat. 12 (2005) 537-541.

[59] V.A. Sole, E. Papillon, M. Cotte, P. Walter, J. Susini, Spectrochim. Acta Part B-Atom. Spectros. 62 (2007) 63-68.

[60] A. Ballarini, P. Benito, G. Fornasari, O. Scelza, A. Vaccari, Int. J. Hydrogen Ener. 38 (2013) 15128-15139.

[61] G. Fiquet, P. Richet, G. Montagnac, Phys. Chem. Minerals 27 (1999) 103-111.

[62] T.K. Sham, Phys. Rev. B 31 (1985) 1888-1902.

[63] F.M.F. de Groot, Z. W. Hu, M.F. Lopez, G. Kaindl, F. Guillot, M. Trone, J. Chem. Phys. 101 (1994) 6570-6576.

[64] K.-i. Shimizu, T. Oda, Y. Sakamoto, Y. Kamiya, H. Yoshida, A. Satsuma, Appl. Catal. B: ha formattato: Inglese (Regno Unito) ha formattato: Inglese (Regno Unito)

ha formattato: Inglese (Regno Unito) Env. 111-112 (2012) 509-514.

[65] A.J. Bard, L.R. Faulknerin (Eds) in Electrochemical methods: Fundamentals and Applications $2^{\text {nd }}$ Edition (2001) Chapter 4, pp 137-155.

[66] Y. Hamlaoui, F. Pedraza, C. Remazeilles, S. Cohendoz, C. Rébéré, L. Tifouti, J. Creus, Mater. Chem. Phys. 113 (2009) 650-657. 


\section{Figure captions}

Figure 1. Secondary SEM images of samples prepared at $-1.2 \mathrm{~V}$ for $2000 \mathrm{~s}$ with different electrolytic solutions: (a) Rh11-HT: $\mathrm{Rh} / \mathrm{Mg} / \mathrm{Al}=11 / 70 / 19$ a.r. \%; (b) $\mathrm{Rh} 5-\mathrm{HT}: \mathrm{Rh} / \mathrm{Mg} / \mathrm{Al}=$ 5/70/25 a.r. \%; (c) Rh2-HT: $\mathrm{Rh} / \mathrm{Mg} / \mathrm{Al}=2 / 70 / 28$ a.r. \%.

Figure 2. Secondary SEM images of samples after calcination at $900{ }^{\circ} \mathrm{C}$ for $12 \mathrm{~h}$. Rh11-c900 (a), Rh5-c900 (b), Rh2-c900 (c).

Figure 3. Elemental distribution maps recorded on a cross-section of a structured rhodium catalyst $(\mathrm{Rh} / \mathrm{Mg} / \mathrm{Al}=11 / 70 / 19$ a.r. \%) based on a metallic foam strut at different stages in the lifecycle. (A) After electrochemical deposition of $\mathrm{Rh}^{3+}, \mathrm{Al}^{3+}$ and $\mathrm{Mg}^{2+}$ cations $\left(100 \times 100 \mu \mathrm{m}^{2}\right.$ ). (B) After calcination of the precursor at $900^{\circ} \mathrm{C}\left(200 \times 236 \mu \mathrm{m}^{2}\right)$. (C) After reduction under hydrogen flow $\left(215 \times 175 \mu \mathrm{m}^{2}\right)$. (D) After use in a catalytic partial oxidation reactor (326 x 222 $\mu \mathrm{m}^{2}$ ). On the Fe-L distribution map (B) the inner and outer surface are marked and the black rectangles indicate regions of which more detailed maps were recorded.

Figure 4. RGB composite maps (details of the maps shown in figure 3) of a cross-section of $\mathrm{RhMgAl}=11 / 70 / 19$ a.r. \% struts after calcination (4b), after reduction (4c) and after CPO (4d). The given numbers mark the spots where XANES measurements were performed; an example of the result of a linear combination fit is given for each state. The typical white-line energies for metallic $\mathrm{Rh}(3005.0 \mathrm{eV})$ and $\mathrm{Rh}$ in a spinel $(3007.0 \mathrm{eV})$ are given.

Figure 5. Evolution of $\mathrm{CH}_{4}$ conversion obtained by catalysts synthesized with different electrolytic solution: $\mathrm{Rh} 11-\mathrm{c} 900, \mathrm{Rh} 5-\mathrm{c} 900$ and $\mathrm{Rh} 2-\mathrm{c} 900 . \mathrm{T}_{\text {oven }}=750{ }^{\circ} \mathrm{C}, \mathrm{CH}_{4} / \mathrm{O}_{2} / \mathrm{He}=2 / 1 / 20$ and 2/1/4 v/v, GHSV $=63,300,38,700,15,250$, and $11,500 \mathrm{~h}^{-1}$.

Figure 6. Average selectivities in $\mathrm{CO}$ and $\mathrm{H}_{2}$ obtained by catalysts synthesized with different electrolytic solution: Rh11-c900, Rh5-c900 and Rh2-c900. $\mathrm{T}_{\text {oven }}=750{ }^{\circ} \mathrm{C}, \mathrm{CH}_{4} / \mathrm{O}_{2} / \mathrm{He}=2 / 1 / 20$ and $2 / 1 / 4 \mathrm{v} / \mathrm{v}$, GHSV $=63,300,38,700,15,250$, and $11,500 \mathrm{~h}^{-1}$. 
Figure 7. Secondary SEM (a) and FEG-SEM (b, c) images of the surface of the Rh5-used cylinder placed in the top of the catalytic bed. (a) Detail of a detached solid; (b) patches of carbon; (c) carbon nanotubes.

Figure 8. Rh particles $(a, b, c)$ and particle sized distribution $\left(a^{*}, b^{*}, c^{*}\right)$ identified in backscattering FEG-SEM images of the spent catalyst cylinders placed on the top of the bed prepared with electrolytic solutions at different $\mathrm{Rh} / \mathrm{Mg} / \mathrm{Al}$ a.r. \% (a, $\left.\mathrm{a}^{*}\right)$ 11/70/19 a.r. \%, Rh11used; (b, b*) 5/70/25 a.r. \%, Rh5-used; (c, c*) 2/70/28 a.r. \%, Rh2-used.

Figure 9. Secondary SEM images of the samples obtained after electrosynthesis at $-1.2 \mathrm{~V}$ for $2000 \mathrm{~s}$ with a $\mathrm{Rh} / \mathrm{Mg} / \mathrm{Al}=5 / 70 / 25$ a.r. \% and total metal concentration of $0.06 \mathrm{M}$, Rh5-HT$0.06 \mathrm{M}$ (a) and after calcination at $900{ }^{\circ} \mathrm{C}$ for $12 \mathrm{~h}, \mathrm{Rh} 5-\mathrm{c} 900-0.06 \mathrm{M}(\mathrm{b})$.

Figure 10. Evolution of $\mathrm{CH}_{4}$ conversion obtained by catalysts synthesized with the 5/70/25 electrolytic solution and different total metal concentration, 0.03M (Rh5-c900) and 0.06M (Rh5-c900-0.06M) and with the bimetallic catalyst, Rh5Ni-c900: 5/15/55/25 a.r. \% $\mathrm{T}_{\text {oven }}=750$ ${ }^{\circ} \mathrm{C}, \mathrm{CH}_{4} / \mathrm{O}_{2} / \mathrm{He}=2 / 1 / 20$ and $2 / 1 / 4 \mathrm{v} / \mathrm{v}, \mathrm{GHSV}=63,300,38,700,15,250$, and 11,500 $\mathrm{h}^{-1}$.

Figure 11. Secondary SEM (a) and FEG-SEM (b, c) images of Rh5-used-0.06M sample placed at the inlet of the catalytic bed.

Figure 12. Secondary SEM image (a) and elemental distribution maps recorded on a crosssection (b) of the bimetallic Rh5Ni-c900 catalyst. 
Table 1. $\mathrm{Rh} / \mathrm{Mg} / \mathrm{Al}$ a.r. in the electrolytic solution and estimation of the $\mathrm{Rh} / \mathrm{Mg} / \mathrm{Al}$ a.r. \% in the coating for the three electrolytic solutions by SEM-EDS analysis. Results correspond to the inspection of 10-15 regions of interest.

\begin{tabular}{|c|c|c|c|c|c|c|c|c|c|}
\hline \multirow{2}{*}{ Atomic ratio \% } & \multicolumn{3}{|c|}{ Rh11-HT } & \multicolumn{3}{|c|}{ Rh5-HT } & \multicolumn{3}{|c|}{ Rh2-HT } \\
\hline & $\mathbf{R h}$ & Mg & Al & Rh & Mg & Al & $\mathbf{R h}$ & Mg & Al \\
\hline $\begin{array}{l}\text { Electrolytic } \\
\text { solution }\end{array}$ & 11 & 70 & 19 & 5 & 70 & 25 & 2 & 78 & 22 \\
\hline Thin film & $2-15$ & $\begin{array}{l}70- \\
85\end{array}$ & $\begin{array}{c}23- \\
13\end{array}$ & 3 & 75 & 22 & 2 & 75 & 23 \\
\hline Outer film & 30 & 10 & 60 & 15 & 20 & 65 & 6 & 13 & 81 \\
\hline
\end{tabular}


Table 2. Summary of the average film thicknesses obtained for the $\mathrm{Rh}_{11} \mathrm{Mg}_{70} \mathrm{Al}_{19}$ struts at the different stages in the lifecycle. The mean value is given as an indication for the average thicknesses of the Rh layer while the standard deviation is given as an indication for the variation of the thicknesses.

\begin{tabular}{l|cccc}
\hline & Rh FWHM $(\boldsymbol{\mu m})$ & Stdev & Mg FWHM $(\boldsymbol{\mu m})$ & Stdev \\
\hline R11-HT & 4.9 & 1.9 & 3.9 & 1.6 \\
R11-c900 & 4.2 & 1.2 & 4.1 & 1.6 \\
R11-red & 9.3 & 3.6 & 7.5 & 3.3 \\
R11-used & 6.7 & 2.6 & 5.0 & 1.9 \\
\hline
\end{tabular}


Figure 1

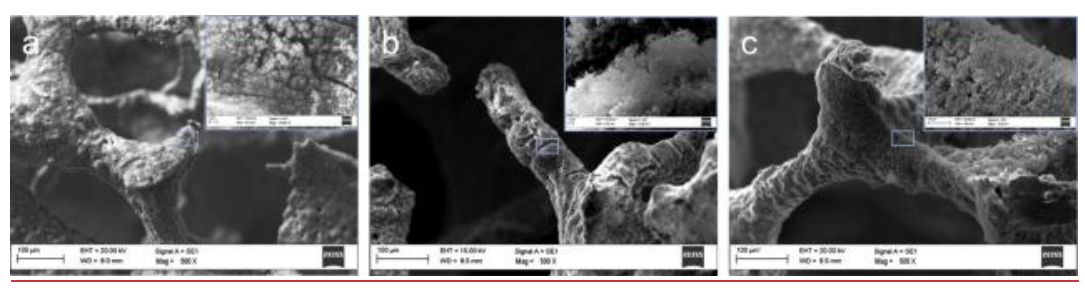

Figure 2

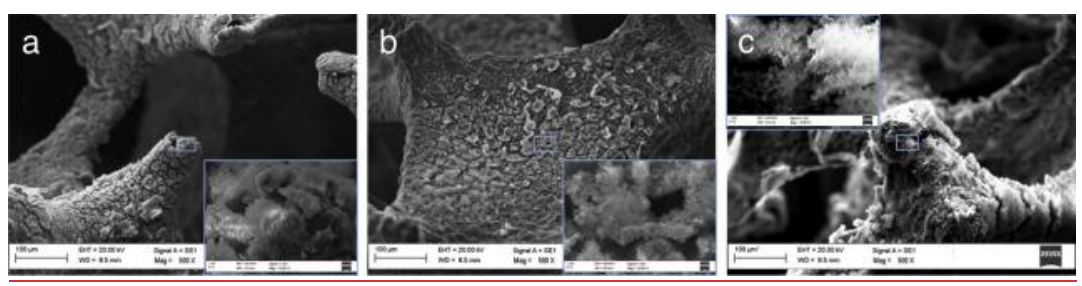


Figure 3

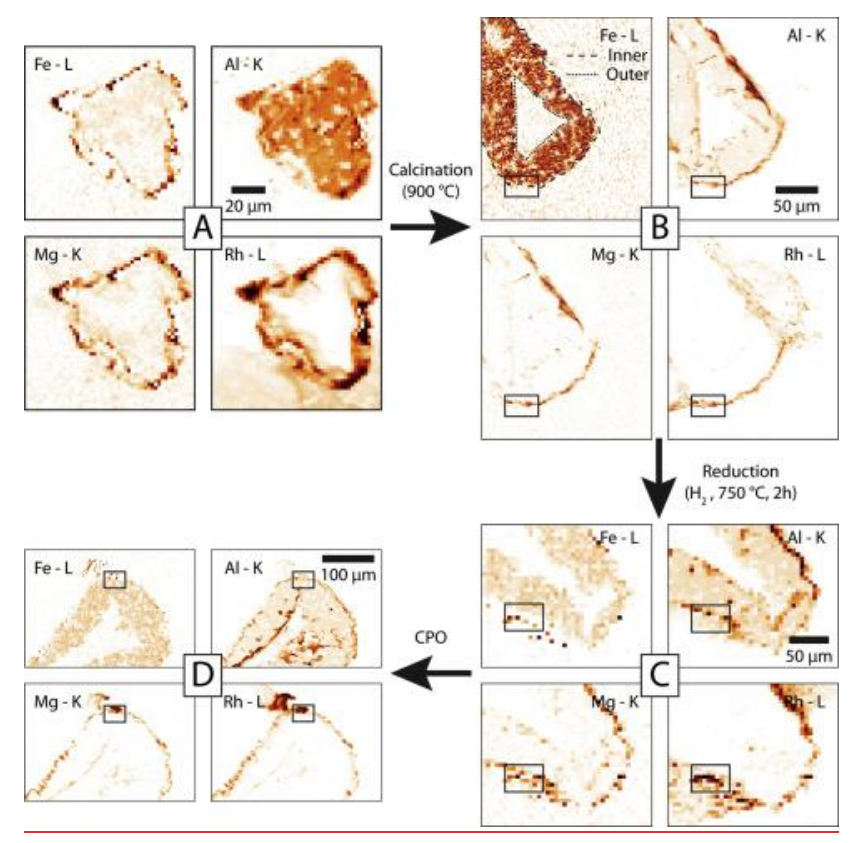


Figure 4
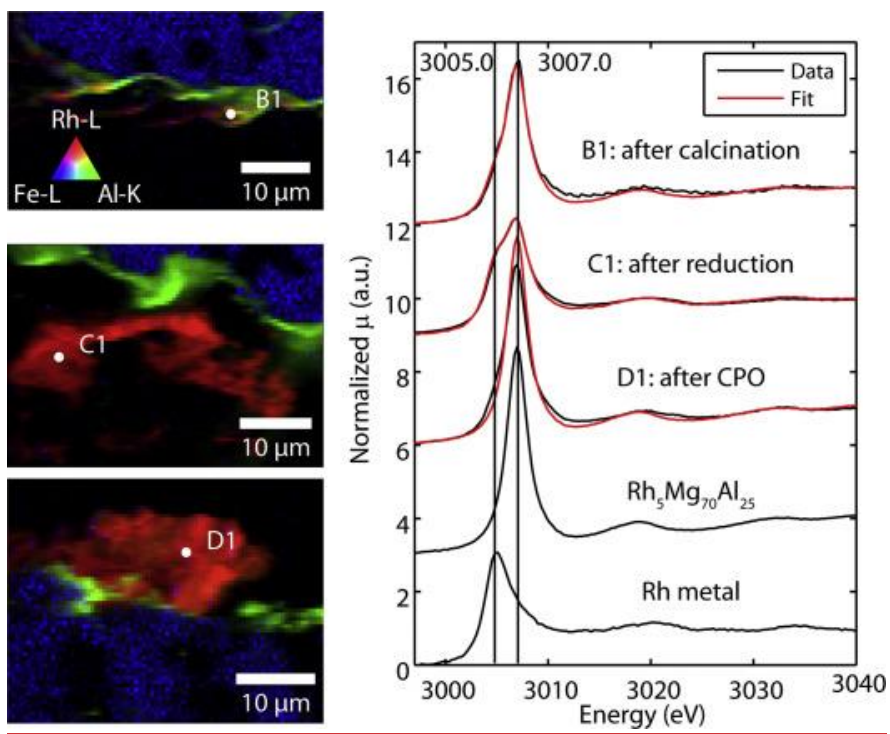
Figure 5

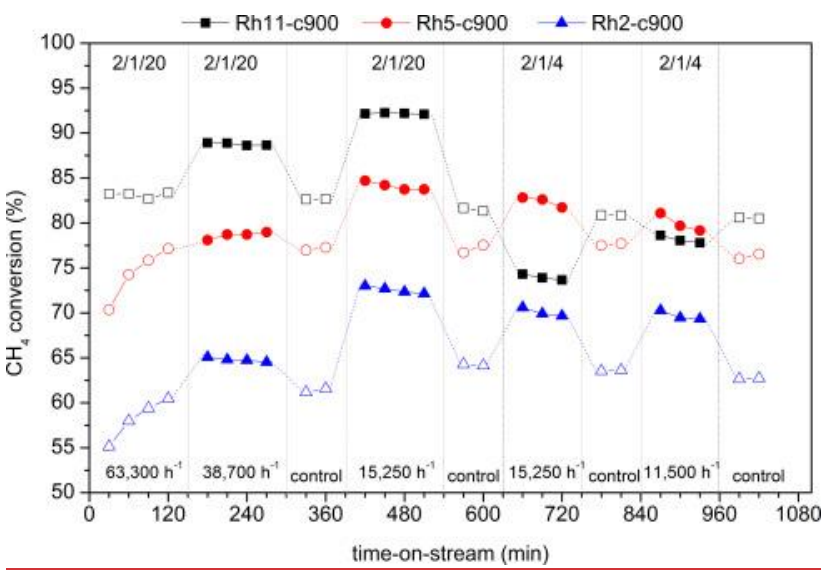

Figure 6

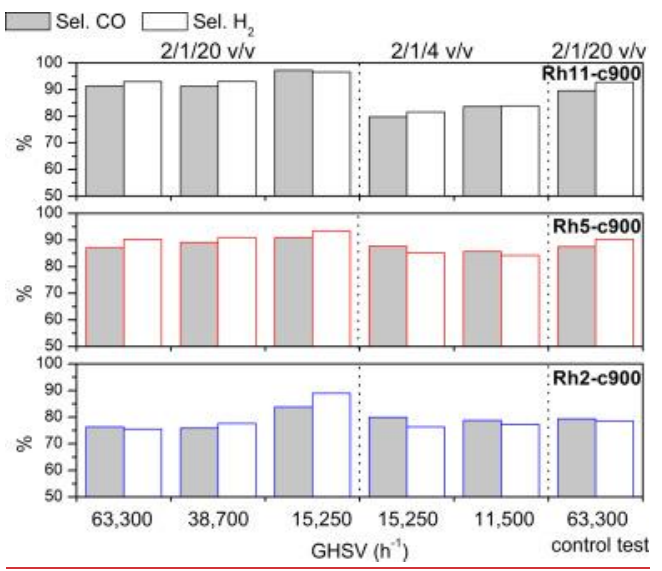


Figure 7

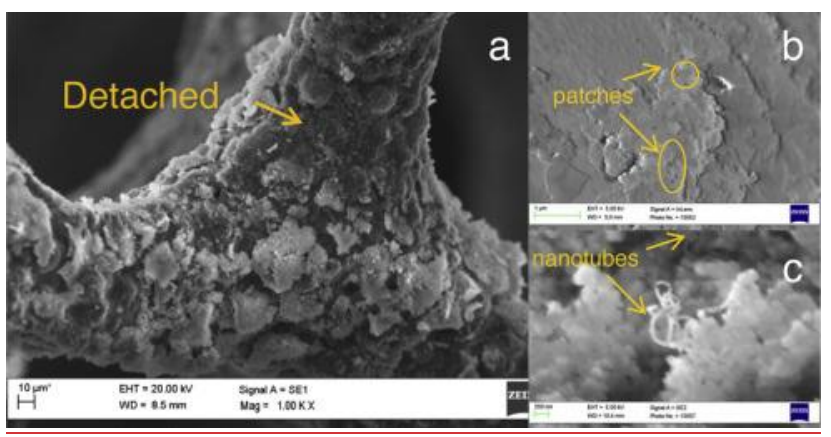

Figure 8
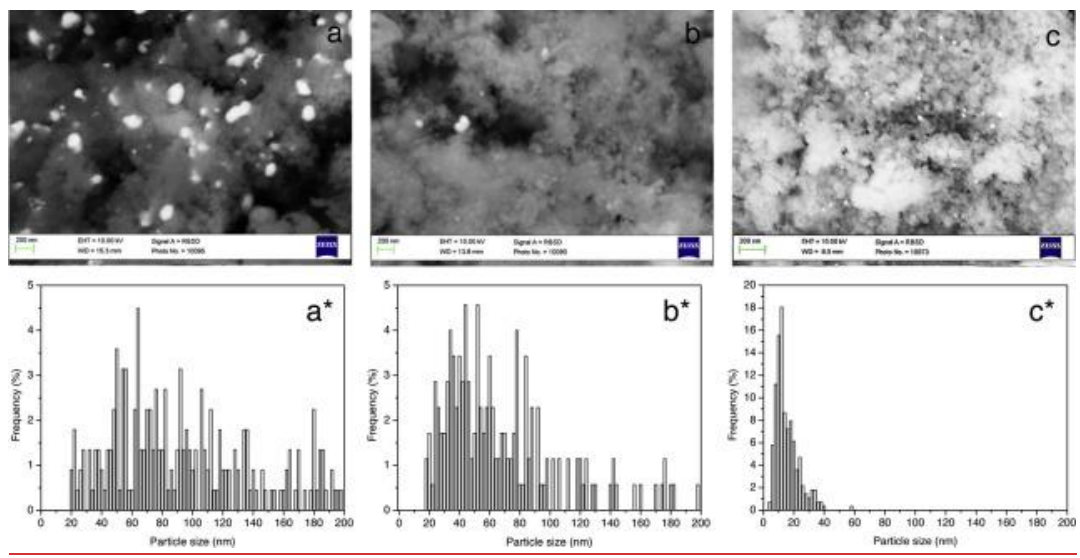
Figure 9

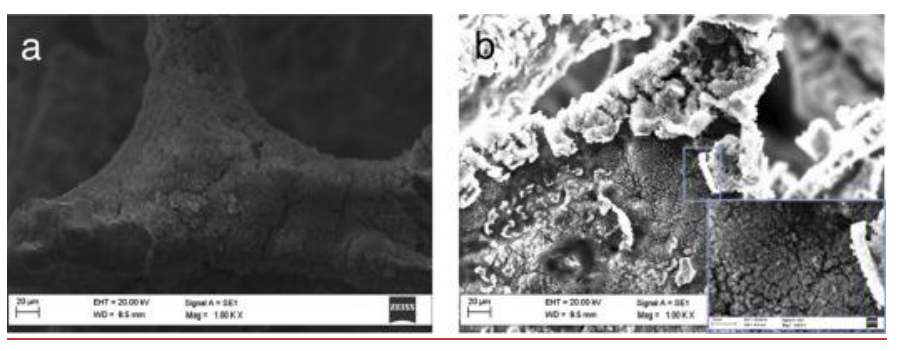

Figure 10

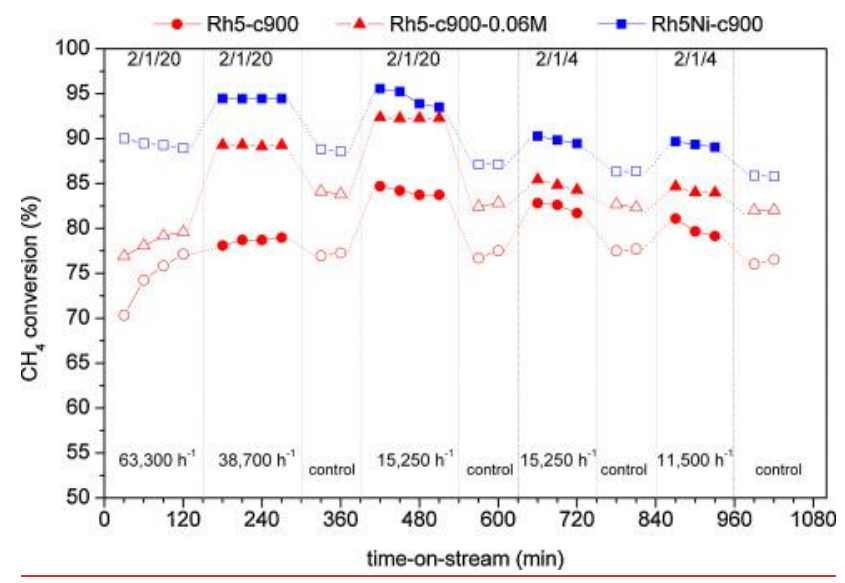


$\underline{\text { Figure } 11}$

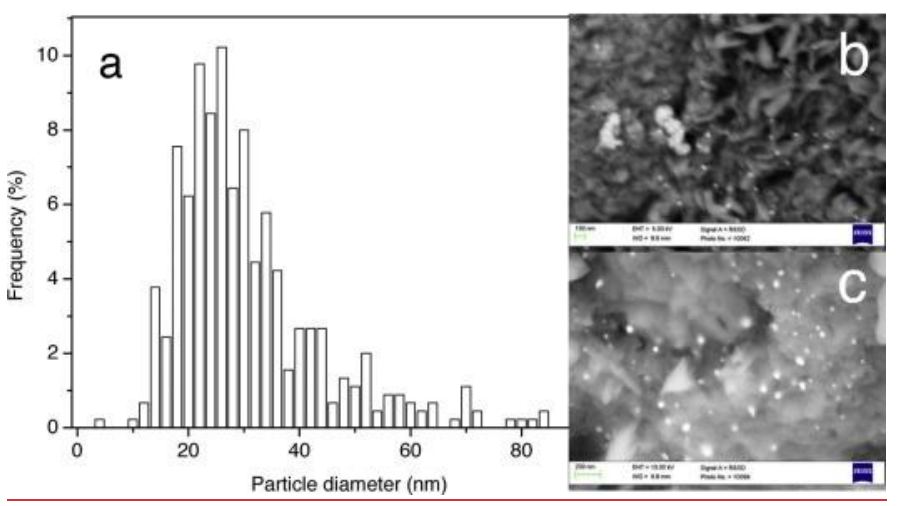

Figure 12

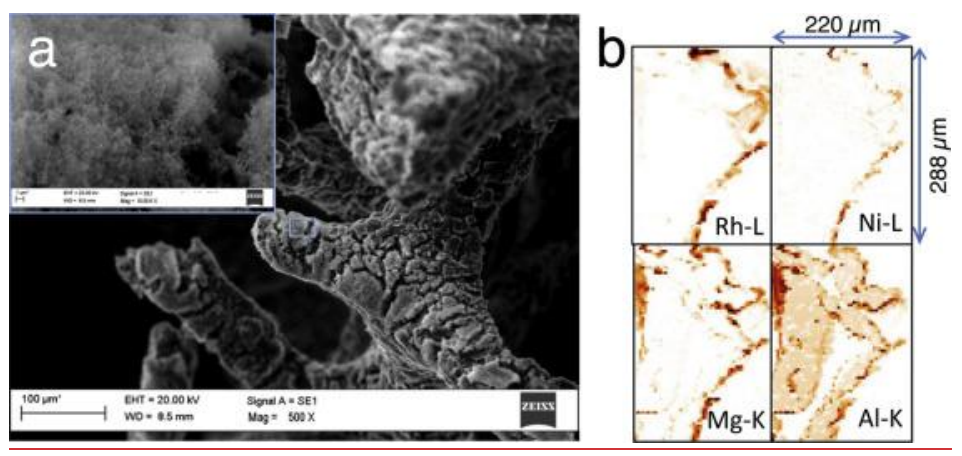

